\title{
The use of a tunneled permanent catheter as temporary vascular access in arteriovenous graft patients for long-term patency
}

\author{
Masatoshi Matsunami ${ }^{1 *}$ (D), Yuki Nakamura ${ }^{1}$, Kiho Tanaka ${ }^{1}$, Yoshifumi Ubara ${ }^{2,3}$ and Yasuo Ishii $^{1}$
}

\begin{abstract}
Background: Generally, the preferred route of vascular access in chronic kidney disease patients is an arteriovenous fistula (AVF) rather than grafts. However, approximately 7\% of 300,000 Japanese hemodialysis (HD) patients continue to dialyze with grafts. In patients who have arteriovenous grafts (AVGs), complications such as thrombosis, hemorrhaging, and infection are common, resulting in lower graft patency. Therefore, in our hospital, to improve graft patency, cases requiring HD immediately after AVG surgery (vascular access occlusion) undergo placement of a tunneled (cuffed) permanent catheter in the internal jugular vein at the time of AVG creation to eliminate preemptive interventions in grafts at risk for thrombosis, hematoma, and infection. We use a tunneled permanent catheter instead of a nontunneled (noncuffed) temporary catheter because nontunneled temporary catheters often require replacement due to catheter-related bacteremia and thrombotic occlusion before the first cannulation.
\end{abstract}

Case presentation: Here, we present four conventional HD patients who had vascular access occlusion and required HD immediately after AVG surgery. The patients underwent placement of a tunneled permanent catheter for temporary vascular access in AVG creation. Once edema in the access arm had completely improved, the first cannulation and then catheter removal were performed.

Conclusions: In conclusion, while the duration between AVG creation and its first use on HD has been prolonged, graft patency has been good. Although additional cases are required to confirm the efficacy of this approach, this finding enables the dialysis community to consider the initiation of AVG use immediately in cases of vascular access occlusion.

Keywords: Hemodialysis, Arteriovenous fistula, Arteriovenous graft, Tunneled permanent catheter, Graft patency

\section{Background}

Generally, the preferred route of vascular access in chronic kidney disease patients is an arteriovenous fistula (AVF) rather than grafts. However, approximately $7 \%$ of 300,000 Japanese hemodialysis (HD) patients continue to dialyze with grafts $[1,2]$. In patients who have arteriovenous grafts (AVGs), complications such as thrombosis, hemorrhaging, and infection are common, resulting in lower graft patency $[3,4]$. Therefore, in our hospital, to improve graft patency, cases requiring HD immediately after AVG surgery (vascular access occlusion) undergo placement of a tunneled permanent catheter (cuffed tunneled catheter) in the internal jugular vein at the time of AVG creation to eliminate preemptive interventions in grafts at risk for thrombosis, hematoma, and infection.

We performed a retrospective analysis of the placement of a tunneled permanent catheter as temporary vascular access in AVG creation for long-term patency.

\footnotetext{
* Correspondence: matsunami-m@toranomon.gr.jp

${ }^{1}$ Department of Surgery, Nephrology Center, Toranomon Hospital, 2-2-2

Toranomon, Minato-ku, Tokyo 105-8470, Japan

Full list of author information is available at the end of the article
}

(c) The Author(s). 2019 Open Access This article is distributed under the terms of the Creative Commons Attribution 4.0 International License (http://creativecommons.org/licenses/by/4.0/), which permits unrestricted use, distribution, and reproduction in any medium, provided you give appropriate credit to the original author(s) and the source, provide a link to the Creative Commons license, and indicate if changes were made. The Creative Commons Public Domain Dedication waiver (http://creativecommons.org/publicdomain/zero/1.0/) applies to the data made available in this article, unless otherwise stated. 


\section{Case presentation \\ Case 1}

A 49-year-old man from Japan was diagnosed with endstage renal disease (ESRD) due to IgA nephritis. Initially, a left wrist radial-cephalic AVF was created for HD. Soon after creation, the AVF was thrombotically occluded, and the patient required AVF reconstruction in the left forearm. However, the reconstructed AVF became occluded again, and we decided to perform brachial-basilic AVG in the right forearm (because of the narrow vascular diameter) with placement of a tunneled permanent catheter (because of the immediate initiation of HD). The implantation graft was an ePTFE-based heparin-coated graft (Propaten; W.L. Gore, Flagstaff, AZ, USA), and cannulation was performed 36 days after its creation. At this point, there was no evidence of thrombosis, edema or infection. The catheter was placed for 44 days with no evidence of thrombosis or catheter-related bacteremia (CRB). At present, 956 days after the operation, the patient is receiving HD stably with no vascular access problems.

\section{Case 2}

An 80-year-old woman from Japan was diagnosed with ESRD of unknown cause 11 years ago, and a radial-cephalic AVF in the left forearm was created for HD. She needed to maintain vein patency with repeated percutaneous venous angioplasty (PTA). Despite the continuation of regular PTAs (every 3 months), her inadequate HD blood flow due to severe stenosis did not improve, so an alternative route of vascular access was considered. We decided to create a brachial-basilic AVG in the right forearm (because of the narrow vascular diameter) with placement of a tunneled permanent catheter (because of the immediate initiation of dialysis). The implantation graft (Vectra; Thoratec Laboratories Corporation, Berkeley, CA, USA) was a polyurethane graft, and cannulation was performed 21 days after its creation. At this point, there was no evidence of thrombosis, edema, or infection. The catheter was placed for 28 days with no evidence of thrombosis or CRB. Thereafter, on postoperative day 139, we performed angiography with PTA, which revealed anastomotic stenosis in the right brachiocephalic vein. PTA using a Sterling balloon dilatation catheter (Boston Scientific, Marlborough, MA, USA) was thus performed and resulted in good dilation.

\section{Case 3}

A 37-year-old man from Japan was diagnosed with ESRD due to purpura nephritis 22 years ago, and an AVF was created for HD. After the patient received his kidney transplantation, the AVF was discarded and chronically thrombosed. When the patient experienced kidney graft loss due to recurrent purpura nephritis, HD needed to be restarted. He had received HD for 15 years via a right forearm radial-cephalic AVF. However, at 37 years of age, the patient had a sudden episode of bleeding from a duodenal ulcer, and severe anemia and hypotension caused AVF occlusion. We placed a brachial-basilic AVG at the same point in the right forearm (because of chronic occlusion and long-discarded AVF access in the left forearm). Usually, a history of AVF creation in the same arm results in prolonged edema, so we decided to perform AVG with placement of a tunneled permanent catheter. The implantation graft was an ePTFE graft (Advanta; Atrium, Hudson, NH, USA), and cannulation was performed 57 days after its creation with perigraft seroma, which resolved spontaneously. The catheter was placed for 58 days with no evidence of thrombosis or CRB. At present, 592 days after the operation, the patient is stably receiving dialysis with no vascular access problems.

\section{Case 4}

A 74-year-old woman from Japan was diagnosed with ESRD due to nephrosclerosis 11 years ago, and a radial-cephalic AVF in the left forearm was created for HD. She needed to maintain vein patency with regular PTAs (every 3 months). However, severe stenosis remained even after dilation with PTA, so we decided to create an AVG at the same point in

Table 1 Characteristics of infections in tunneled permanent catheters versus nontunneled temporary catheters

\begin{tabular}{|c|c|c|c|c|c|c|}
\hline & $\begin{array}{l}\text { Number of } \\
\text { catheters inserted }\end{array}$ & $\begin{array}{l}\text { Number of } \\
\text { infection }\end{array}$ & $\begin{array}{l}\text { Observation } \\
\text { period }\end{array}$ & $\begin{array}{l}\text { Infection rates per } \\
1000 \text { catheter-days }\end{array}$ & Infection relative risk & Reference \\
\hline Tunneled permanent catheter & 37 & 6 & 36-month period & 2.9 & RR 3.7 (1.8-7.5), $p<0.001$ & Weijmer et al. [6] \\
\hline Nontunneled temporary catheter & 235 & 52 & & 12.8 & & \\
\hline Tunneled permanent catheter & 36 & NA & 16-month period & NA & $\operatorname{RR} 1.4(0.6-3.4), p=0.41$ & Mendu et al. [9] \\
\hline Nontunneled temporary catheter & 91 & NA & & NA & & \\
\hline Tunneled permanent catheter & 310 & 86 & 24-month period & 5.5 & - & Saad et al. [10] \\
\hline Tunneled permanent catheter & 182 & 28 & 16-month period & 5.8 & - & Rocklin et al. [11] \\
\hline Tunneled permanent catheter & 108 (Patients) & 92 & 12-month period & 4.6 & - & Lee et al. [12] \\
\hline
\end{tabular}


Table 2 Proportions of AVG patients with a tunneled permanent catheter and their postoperative course

\begin{tabular}{|c|c|c|c|c|c|c|c|c|c|}
\hline \multirow[t]{2}{*}{ No } & \multirow[t]{2}{*}{ Graft } & \multicolumn{4}{|c|}{ Patient demography } & \multicolumn{4}{|c|}{ Postoperative course } \\
\hline & & Age & Sex & Cause of renal failure & Catheter & First cannulation & Catheter removal & Complications & Follow up \\
\hline 1 & Propaten & 49 & M & IgA nephropathy & Bio-Flex Tesio & 36 days & 44 days & - & 956 days \\
\hline 2 & Thoratec (Vectra) & 80 & $\mathrm{~F}$ & Unknown & Split Stream & 21 days & 28 days & Stenosis (PTA) & 778 days \\
\hline 3 & Advanta & 37 & M & Purpura nephritis & Split Stream & 57 days & 58 days & Seroma & 592 days \\
\hline 4 & Advanta & 74 & $\mathrm{~F}$ & Nephrosclerosis & Split Stream & 94 days & 105 days & Stenosis (PTA) & 564 days \\
\hline
\end{tabular}

PTA percutaneous transluminal angioplasty

the left forearm (because the patient requested, we use the same arm) with placement of a tunneled permanent catheter (because of the immediate initiation of dialysis). The implantation graft was an ePTFE graft (Advanta), and cannulation was performed 94 days after its creation. At this point, there was no evidence of thrombosis, edema, or infection. The catheter was placed for 105 days with no evidence of thrombosis or CRB. On postoperative day 79, we performed angiography with PTA, which revealed anastomotic stenosis in the left brachiocephalic vein. PTA using the Sterling balloon dilatation catheter was thus performed and resulted in good dilation.

\section{Discussion and conclusions}

We use a tunneled (cuffed) permanent catheter instead of a nontunneled (noncuffed) temporary catheter because nontunneled temporary catheters often require replacement due to CRB and thrombotic occlusion before the first cannulation. In contrast, with a tunneled permanent catheter, a polyester cuff positioned approximately $2 \mathrm{~cm}$ from the skin exit site allows tissue ingrowth (biofilm formation) to function as an anchor and prevent bacterial migration [5]. This feature is associated with a marked reduction in the risk of CRB [6-8]. In addition, a tunneled permanent catheter facilitates living with a catheter, such as dressing, cleaning, and showering, which may improve the patients' quality of life. Once edema in the access arm had completely improved, the first cannulation and then catheter removal were performed.

Our search of the literature revealed few reported cases comparing the performance of a tunneled permanent catheter versus a nontunneled temporary catheter in $\mathrm{HD}$ patients [6, 9-12] (Table 1). While these clinical outcomes may be related to variations in several parameters, such as catheter type, inserted position, duration of use, and catheter management (hygiene or use of antibiotics), nontunneled temporary catheters have demonstrated significantly higher infection rates than tunneled permanent catheters.

Our study included a total of four conventional HD patients who had vascular access occlusion and required HD immediately after AVG surgery. The reason why the number of samples is still small is that our procedure has only been started recently, and in the cases of thrombotic occlusion, we are trying to reconstruct AVF in the upstream native shunt vessel. However, as the
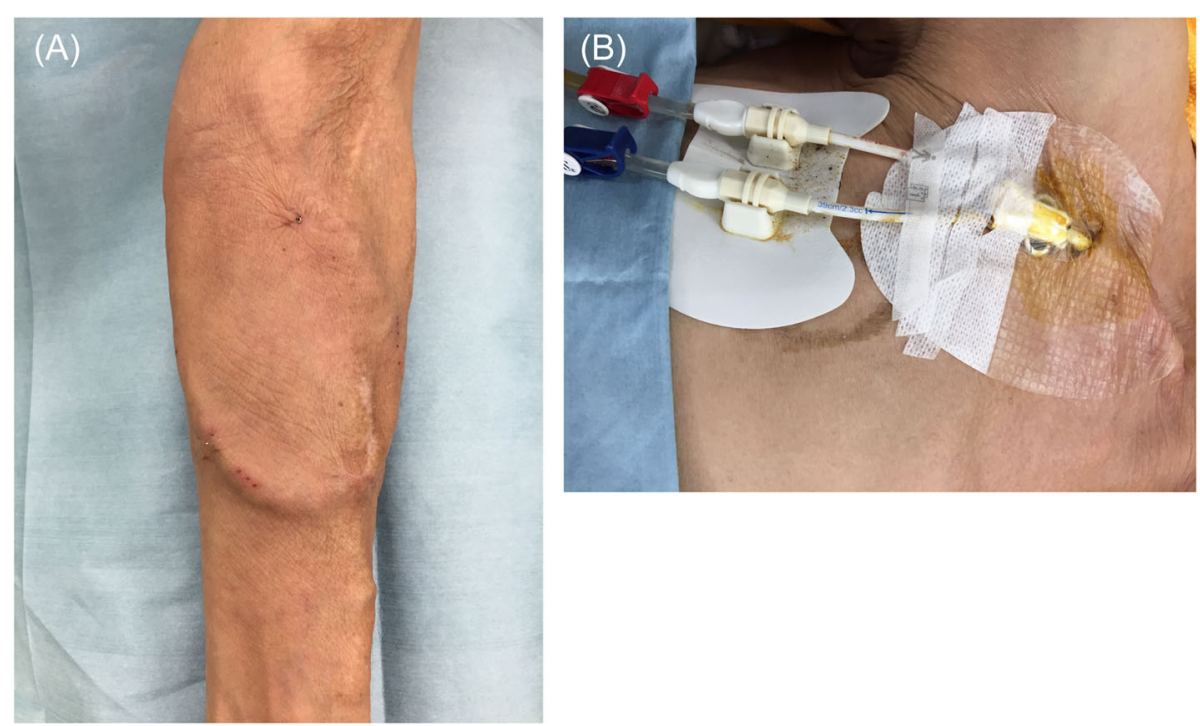

Fig. 1 Left forearm loop graft (a) and Split Stream catheter in the right internal jugular vein (b), both at catheter removal, with no complications 
number of cases of graft use gradually increases, our procedure (AVG with tunneled permanent catheter) will likely see increased use in the near future.

The original shunt vessels have often already developed following AVF upstream reconstruction in thrombotic occlusion cases; thus, HD can be resumed with high blood flow despite immediate puncture after operation. Furthermore, native shunt vessels result in fewer infections than grafts; thus, we did not include AVF reconstruction cases in this study.

On the other hand, the immediate-use ePTFE graft (Acuseal; W. L. Gore \& Associates, Newark, DE, USA) seems to be widely used overseas [13, 14]. However, in Japan, the sales and use of Acuseal had just been approved in 2015, and thus, there are no long-term clinical reports describing its use. Therefore, those grafts were not included in this study either.

All AVG surgeries were performed under local and brachial plexus block anesthesia. We used loop forearm grafts that were anastomosed to the brachial artery and basilic vein. There were no selection criteria for graft types. The graft efficacy, first cannulation date, postoperative complications, and graft patency over 1-year follow-up were evaluated. The details of individual patients and outcomes are summarized in Table 2.

The implantation grafts were cannulated with 16gauge needles at a mean of 52 days after their creation, provided that there was no evidence of thrombosis, edema, or infection. The time between graft implantation and first cannulation was longer in patients 3 and 4 than in the others. This might be explained by the fact that edema was prolonged due to prior AVF creation in the same arm. The catheter was placed for a mean of 58 days with no evidence of thrombosis or CRB. Postoperative complications after 1 year were seroma $(n=1)$ and stenosis requiring PTA $(n=2)$ (Table 2). The cumulative primary-assisted patency after 1 year was $100 \%$. Figure 1 shows a representative case at catheter removal, with no edema in the access arm (a) and no catheter troubles (b).

In conclusion, this study showed that while the duration between AVG creation and its first use on HD has been prolonged, graft patency has been good. Although additional cases are required to confirm the efficacy of this approach, this finding enables the dialysis community to consider the initiation of AVG use immediately in cases of vascular access occlusion.

\section{Abbreviations}

AVF: Arteriovenous fistula; AVG: Arteriovenous graft; CRB: Catheter-related bacteremia; ESRD: End-stage renal disease; HD: Hemodialysis

\section{Acknowledgements}

The authors would like to thank Drs. Shun Watanabe, Masahiko Oguro, Daisuke Ikuma, Hiroki Mizuno, Rikako Hiramatsu, Keiichi Sumida, Masayuki Yamanouchi, Tatsuya Suwabe, and Naoki Sawa for their careful patient management at Toranomon Hospital Kajigaya in Kanagawa, Japan.

\section{Authors' contributions}

MM designed and wrote the manuscript. YN and KT treated the patients. YU and $\mathrm{YI}$ supervised the vascular access program and corrected the manuscript. All authors read and approved the final manuscript.

\section{Funding}

No funding was obtained for this study.

Availability of data and materials

All data supporting our findings are contained within the manuscript.

Ethics approval and consent to participate

Not applicable.

\section{Consent for publication}

Written informed consent was obtained from the patients to publish this case report and any accompanying images. A copy of the written consent form is available for review by the editor of this journal.

\section{Competing interests}

The authors declare that they have no competing interests.

\section{Author details}

'Department of Surgery, Nephrology Center, Toranomon Hospital, 2-2-2 Toranomon, Minato-ku, Tokyo 105-8470, Japan. ${ }^{2}$ Nephrology Center, Toranomon Hospital, Tokyo, Japan. ${ }^{3}$ Okinaka Memorial Institute for Medical Research, Tokyo, Japan.

Received: 25 March 2019 Accepted: 27 August 2019

Published online: 06 September 2019

\section{References}

1. Masakane I, Taniguchi M, Nakai S, Tsuchida K, Wada A, Ogata S, Hasegawa T, Hamano T, Hanafusa N, Hoshino J, et al. Annual dialysis data report 2016, JSDT renal data registry. Adv Ren Replace Ther. 2018;4(1):45.

2. Masakane I, Taniguchi M, Nakai S, Tsuchida K, Goto S, Wada A, Ogata S, Hasegawa T, Hamano T, Hanafusa N, et al. Annual Dialysis data report 2015, JSDT renal data registry. Adv Ren Replace Ther. 2018;4(1):19.

3. Harish A, Allon M. Arteriovenous graft infection: a comparison of thigh and upper extremity grafts. Clin J Am Soc Nephrol. 2011;6(7):1739-43.

4. Woo K, Lok CE. New insights into dialysis vascular access: what is the optimal vascular access type and timing of access creation in CKD and dialysis patients? Clin J Am Soc Nephrol. 2016;11(8):1487-94.

5. Gallieni M, Brenna I, Brunini F, Mezzina N, Pasho S, Giordano A. Dialysis central venous catheter types and performance. J Vasc Access. 2014; 15(Suppl 7):S140-6.

6. Weijmer MC, Vervloet MG, ter Wee PM. Compared to tunnelled cuffed haemodialysis catheters, temporary untunnelled catheters are associated with more complications already within 2 weeks of use. Nephrol Dial Transplant. 2004;19(3):670-7.

7. Klouche K, Amigues L, Deleuze S, Beraud JJ, Canaud B. Complications, effects on dialysis dose, and survival of tunneled femoral dialysis catheters in acute renal failure. Am J Kidney Dis. 2007:49(1):99-108.

8. Clark EG, Barsuk JH. Temporary hemodialysis catheters: recent advances. Kidney Int. 2014;86(5):888-95.

9. Mendu ML, May MF, Kaze AD, Graham DA, Cui S, Chen ME, Shin N, Aizer AA, Waikar SS. Non-tunneled versus tunneled dialysis catheters for acute kidney injury requiring renal replacement therapy: a prospective cohort study. BMC Nephrol. 2017;18(1):351.

10. Saad TF. Bacteremia associated with tunneled, cuffed hemodialysis catheters. Am J Kidney Dis. 1999;34(6):1114-24.

11. Rocklin MA, Dwight CA, Callen $\sqcup$, Bispham BZ, Spiegel DM. Comparison of cuffed tunneled hemodialysis catheter survival. Am J Kidney Dis. 2001;37(3):557-63.

12. Lee T, Barker J, Allon M. Tunneled catheters in hemodialysis patients: reasons and subsequent outcomes. Am J Kidney Dis. 2005;46(3):501-8. 
13. Wagner JK, Dillavou E, Nag U, Ali AA, Truong S, Chaer R, Hager E, Yuo T, Makaroun M, Avgerinos ED. Immediate-access grafts provide comparable patency to standard grafts, with fewer reinterventions and catheter-related complications. J Vasc Surg. 2019;69(3):883-9.

14. Wagner JK, Truong S, Chaer R, Dillavou E, Hager E, Yuo T, Makaroun M, Avgerinos ED. Current experience and midterm follow-up of immediateaccess arteriovenous grafts. Ann Vasc Surg. 2018:53:123-7.

\section{Publisher's Note}

Springer Nature remains neutral with regard to jurisdictional claims in published maps and institutional affiliations.

Ready to submit your research? Choose BMC and benefit from:

- fast, convenient online submission

- thorough peer review by experienced researchers in your field

- rapid publication on acceptance

- support for research data, including large and complex data types

- gold Open Access which fosters wider collaboration and increased citations

- maximum visibility for your research: over $100 \mathrm{M}$ website views per year

At BMC, research is always in progress.

Learn more biomedcentral.com/submissions 